\title{
Survey explores influences on youth workforce preparation
}

\author{
Ella R. Madsen \\ Susan Donohue \\ - Ann Brosnahan \\ Isela Valdez
}

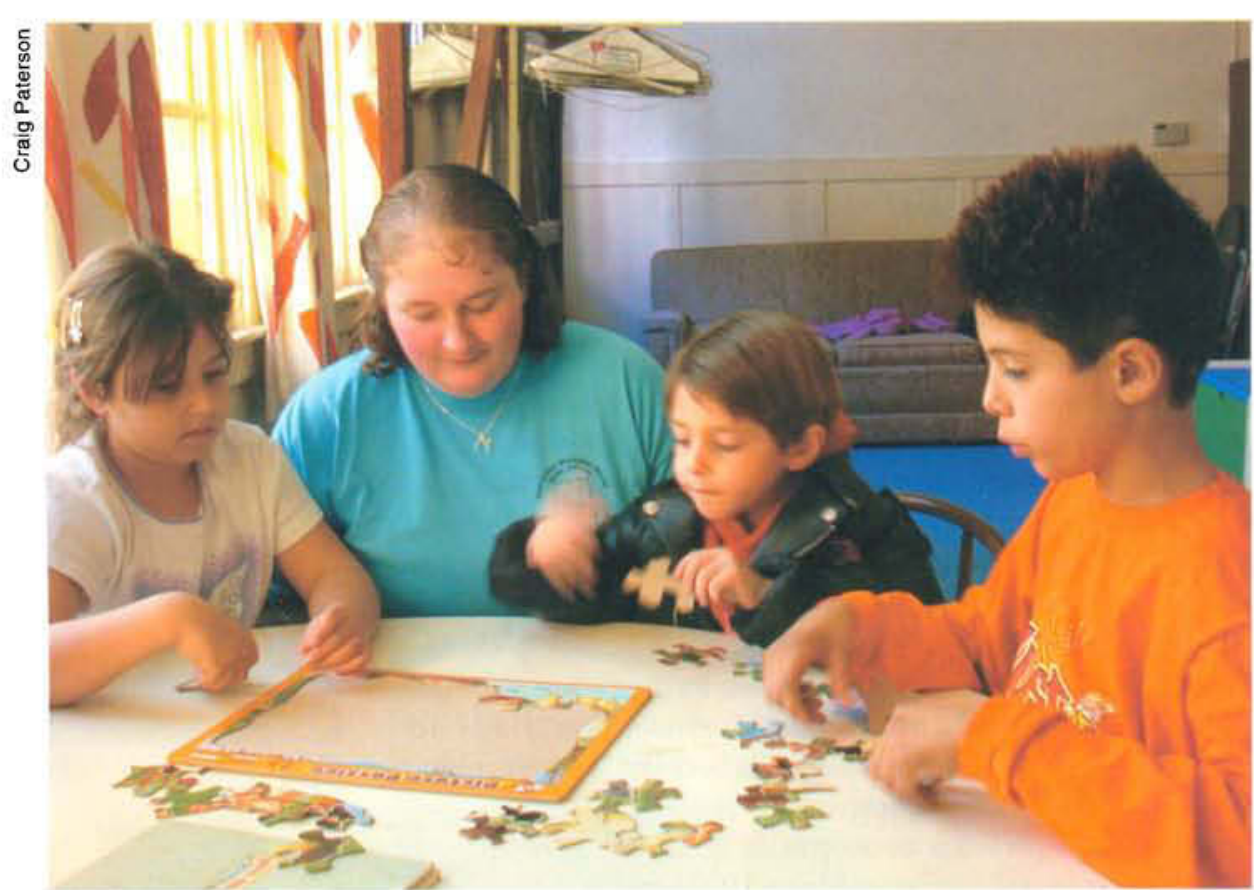

The career exploration network for youth includes a combination of school, parents, youth groups and community programs. In Vallejo, Monica Macdonald, a 2001 graduate of Hogan High School, assists at a day care center.

To develop programs and resources that help youth succeed in today's workplace, it is important to understand the various factors that influence their career exploration and decisionmaking process. A survey was conducted with 1,433 high school seniors in Northern California. Results indicate that the number of young people planning to seek education or training beyond high school continues to rise. There are distinct differences in the educational aspirations and expectations among different ethnic groups. The majority of students surveyed did not use school counseling services, and among those who did only a small percentage found them helpful. For most youth, parents are the primary source of help in preparing for further education and work. There is a strong positive relationship between academic achievement, and both participation in extracurricular activities and positive parent-child relations.
Today's workplace is characterized as technology creates new possibilities and current practices become obsolete. Occupations disappear and new ones are created. The impact of global economic forces is felt even in the most sheltered communities (Greenwald 1997). Success in this workplace requires preparation throughout childhood and youth as well as planning on the part of young people (CCAD 1989).

Throughout young people's lives a variety of factors influence their ideas and attitudes about work and their place in the world of work. The need to identify and understand the factors that lead to productive career planning and decision-making becomes more urgent as growing numbers of young people find themselves ill prepared for today's job market (SCANS 1991, 1992). In addition to the need for basic skills and competencies, young people must be able to make career choices and decisions that will lead to a productive and satisfying future (Stevenson et al. 1998). However, they often approach career exploration and decision-making with ambiguity, uncertainty and stress. After high school, many young people - uncertain about what they want to do - move from school to school, school to job, job to job, or job to school, frustrated by the lack of information and guidance that would help them plan effectively for the future (Santrock 1995).

Providing all youth with the appropriate information, opportunities for career exploration, and guidance to prepare for the future is a challenging and important task. Schools, parents and families, youth-serving organizations and community programs are all valuable components of their careerexploration support networks (Bergman and Killen 1999; Lamborn et al. 1991; Rehberg and Westby 1967; Trice 1991; Vondracek 1993). These efforts, however, should be grounded in a clear understanding of the develop- 


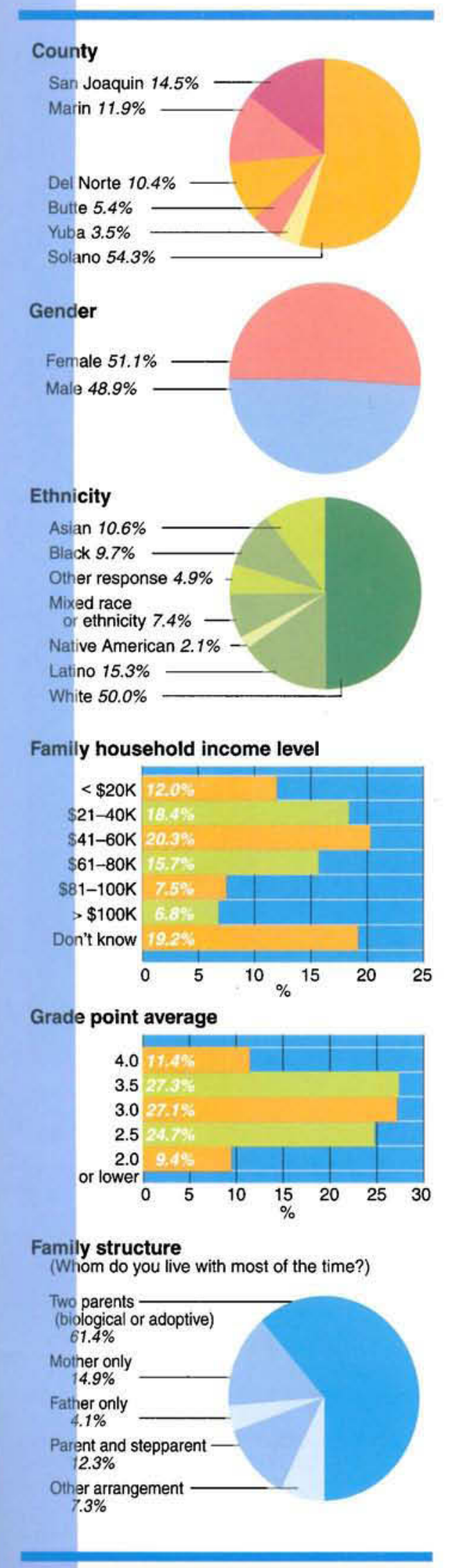

Fig. 1. Demographic characteristics of high school survey sample. Percentages include valid cases only (missing data excluded). mental processes related to career choice, as well as the factors that will lead adolescents to think about their life work in productive and appropriate ways (Harren 1979).

\section{Seniors provide insight}

The "Preparing Adolescents for the World of Work" study aims to increase understanding of influential factors in young people's decisions and preparation for the world of work. In spring 1997, 1,433 high school seniors from six counties in Northern California were surveyed through a collaborative research effort by UC's 4-H Center for Youth Development (CYD) and county 4-H youth development advisors. The advisors contacted public high schools in the six counties, and nine schools agreed to participate. The survey was administered by graduate students and 4-H CYD research staff during a regular 50-minute class period.

The survey consisted of $120 \mathrm{mul}-$ tiple choice, yes/no, and Likertscale type questions plus two additional measures: The Career Key, a 60-question assessment of occupational interests developed by Lawrence K. Jones of North Carolina State University, and the Task Specific Occupational Self-Efficacy Scale developed by Osipow, Rooney and Temple of Ohio State University. Most participants completed the first two sections of the survey, which form the basis for this report. Data was gathered on demographic characteristics, school experiences, extracurricular activities, work experiences (see p. 55), support networks, educational and career expectations, and career exploration and decisionmaking activities.

The students surveyed represent a cross-section of California youth (fig. 1). The ethnic distribution of the participants is representative of California's population with the exception of Latinos, who make up $32.1 \%$ of the state's high school seniors but only $16 \%$ of the survey sample (California Student Trends 2001).

\section{Aspirations and expectations}

Across the country, more and more high school graduates are seeking postsecondary education as entrylevel positions demand more sophisticated skills and the wage disparity between trained and untrained workers increases (Stevenson et al. 1998). Students in this study were asked how far they aspired to go in their education as well as what level of schooling they really expected to attain. Overall, $83 \%$ aspired to a bachelor's degree or higher, yet only $72 \%$ actually expected to attain this goal (fig. 2A). Girls exceeded boys in both their aspirations and expectations for a college degree. In terms of ethnicity, white, Asian, black and mixed-race students were fairly similar in their aspirations for a college degree $(84 \%$ to $88 \%$ ), compared with only $72 \%$ of Latino students. The percentage of each group that actually expected to achieve their educational aspirations was lower in all groups, but especially so among Latinos ( $72 \%$ aspired versus $56 \%$ expected) and blacks (85\% aspired versus $66 \%$ expected). Twenty percent of the students reported no perceived barriers and $47 \%$ cited lack of money as the greatest obstacle to achieving their educational aspirations, followed by lack of information (13\%) and low grades $(12 \%)$ (fig. $2 \mathrm{~B})$.

Who are the students who do not believe they will go as far in their education as they would like? We looked more closely at cases in which students' reported aspirations exceeded their expectations, a category that included $37.5 \%$ of our respondents (fig. 3). Neither gender nor current work status was a discriminating factor between students who expected to achieve their educational aspirations and those who did not, but level of reported family income was. As the self-reported family income increased, 
IN this series of research reports, UC's 4-H Center for Youth Development and 4-H youth development advisors provide scientific underpinnings for the development of workforce preparation programs that will meet the needs of California's diverse and growing population of youth. Several educational, economic and social trends will have implications for American youth as they prepare to enter the world of work at the beginning of the 21st century.

Qualified workers. The American labor force seriously lacks qualified workers. The 1991 Secretary's Commission on Achieving Necessary Skills (SCANS), prepared by the Department of Labor, identified the characteristics a person needs in order to be productive in today's global economy, including foundation skills (such as reading, writing and math) and workplace competencies (such as interpersonal skills, communication and using technology effectively). Unfortunately, more than half the youth leaving high school lack these basic skills and competencies. Consequently, employers are finding it necessary to import employees or export jobs (SCANS 1991).

In 1997, Joseph Stiglitz, chairman of the President's Council of Economic Advisors stated: "In the 19th century, the frontier of America was moving from agriculture to manufacturing. Today the frontier is going from manufacturing to services and technology, much of which can be exported." In addition to technology, qualified teachers, nurses, physical therapists, accountants and skilled craftsman are also in high demand (Bureau of Labor Statistics 1999; Greenwald 1997). At the same time, entry-level positions generally require more sophisticated skills, and high school graduates are seldom able to advance to a position that provides a comfortable living wage (Stevenson et al. 1998).

Earning power. The disparity in earning power between workers of varying educational levels continues to grow. Between 1973 and 1995 the real hourly wages of workers without a high school diploma declined by over $23 \%$, with a high school diploma by more than $14 \%$, and with some college education by $13 \%$. At the same time the earning power of college graduates and those with ad-
The 4-H National Center for Workforce Preparation has formed several partnerships with industry to prepare youth for future employment. California 4- $\mathrm{H}$ members from Merced attended a 5-day hands-on training and mentoring program at the Honda Technical Training Center near Stockton. Cesar Aguilar, top and center right, and Paul Mahacek, bottom (center), learned how engines operate, as well as the chemistry of batteries, and combustion, physics and metrics. Photos courtesy of Richard Mahacek.

vanced degrees increased $4.3 \%$ and $12.1 \%$, respectively (Stevenson et al. 1998).

Specialized training. Due to tightening budgets and increasing emphasis on college preparation, vocational training in high school has greatly diminished (the Regional Occupational Program being a wonderful exception). The federally funded School-to-Work or Career Initiative has helped to link academic learning to applications in the workplace, but the major emphasis is still on college preparation. In contrast, in countries such as Japan and Germany there is a tradition of tight linkages between secondary schools and the worlds of work and college (Stevenson et al. 1998). These types of alliances provide young people with opportunities to understand how academic experiences are relevant to their future work as well as to develop important skills and competencies.

Nationwide response. Two major initiatives have been put forth on the national level in recent years to address these problems. First, in 1996 the Cooperative State Research, Education and Extension Service of the USDA instituted the National Workforce Preparation Initiative, in order to "marshal the extension, teaching and research resources of the landgrant university system to address workforce preparation throughout the country."

Second, under the direction of the $\mathrm{Na}$ tional 4-H Council, the National Center for Workforce Preparation was established in 1996. The center developed a model based on SCANS and launched a multifaceted program, called Preparing Youth for Employable Futures. The center has partnered with a variety of major corporations to offer mentoring, internship and apprentice programs as well as grants to support local programs.
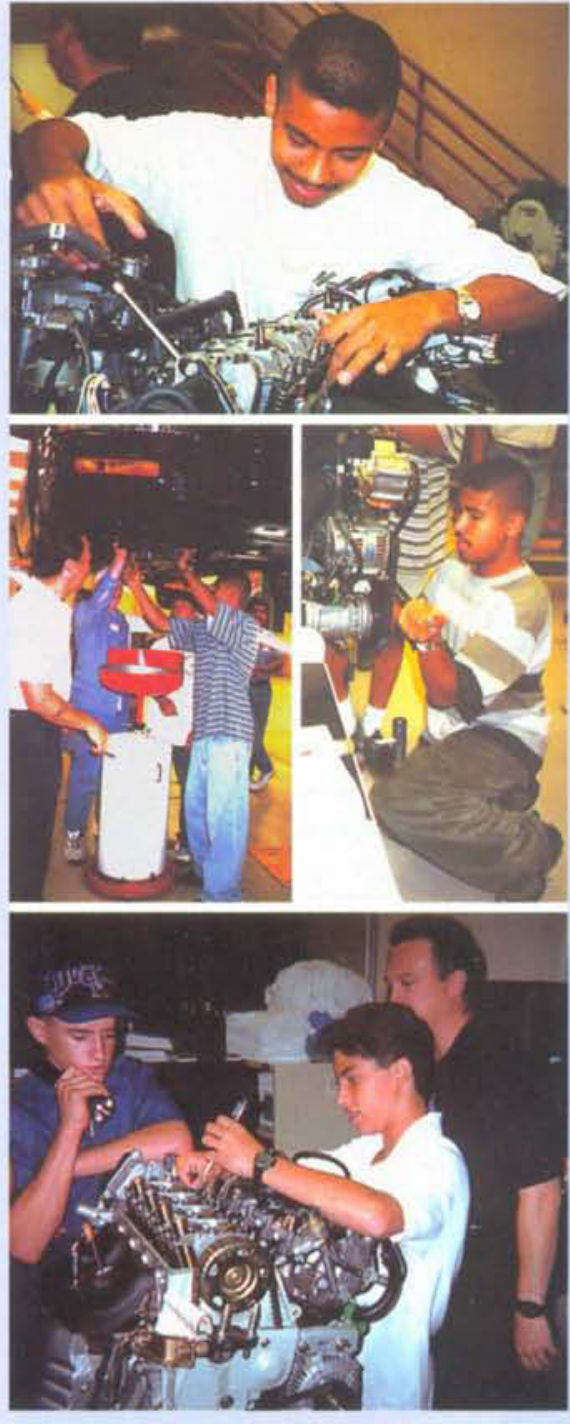

E.R. Madsen is Research Associate, 4-H Center for Youth Development, Department of Human and Community Development, UC Davis.

\section{References}

Bureau of Labor Statistics. 1999. Employment Projections for 1998-2008. http:// stats.bls.gov/emphome.htm.

Greenwald J. 1997 June 20. Where the jobs are. Time:54-61.

[SCANS] Secretary's Commission on Achieving Necessary Skills. 1991. What Work Requires of Schools: A SCANS Report for America 2000. Washington, DC: US Dept Labor. $61 \mathrm{p}$.

Stevenson DL, Kochanek J, Schneider B. 1998. Making the transition from high school: Recent trends and policies. In: Borman $\mathrm{K}$. Schneider B (eds.). The Adolescent Years: Social Influences and Educational Challenges; 97 th Yearbook of National Society for Study of Education. Chicago: Univ Chicago Pr. p 207-26. 

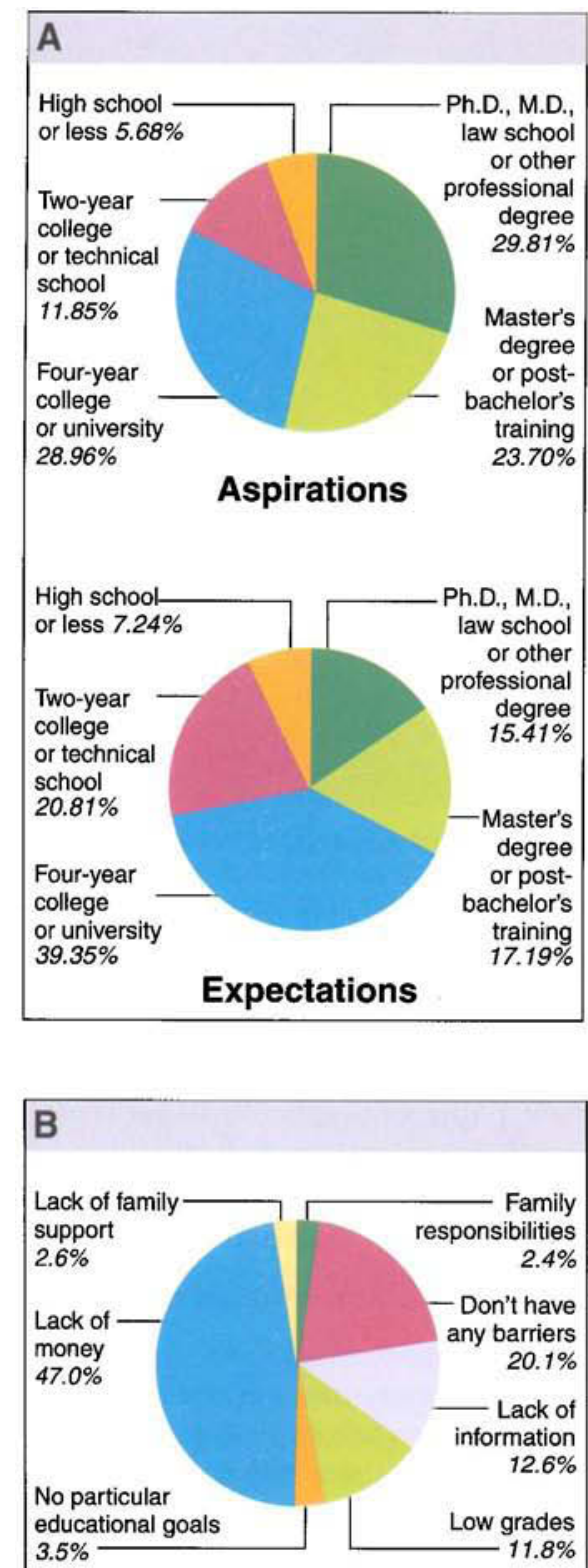

\section{Greatest perceived barriers}

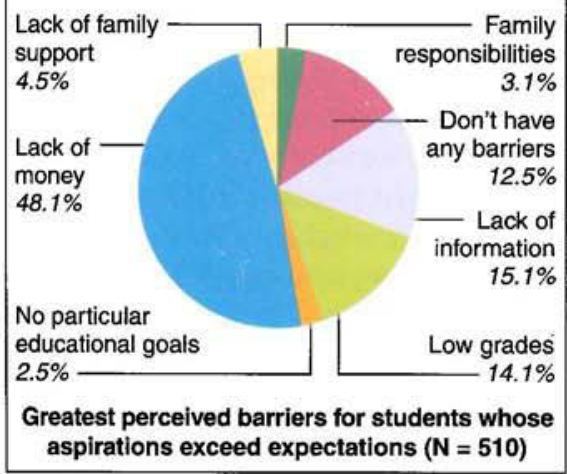

Fig. 2. (A) Students' educational aspirations and expectations, and (B) greatest perceived barriers to accomplishing educational goals. the percentage of students expecting to realize their aspired educational goals also increased.

Combined with the finding that lack of money was most often cited as the obstacle to educational ambitions, it appears likely that a certain amount of the difference between educational aspirations and expectations may be driven by financial factors. However, the influence of other factors, such as parental encouragement and support, needs to be explored, considering that (a) students whose expectations matched their aspirations perceived the barriers to educational goals in much the same way as those students whose expectations were lower than their aspirations; and (b) nearly half the students in the lowest income group did expect to achieve their educational goals.

Not all students seeking postsecondary education or training aspired to a 4-year college degree. Over the past few years an increasing percentage of students have been attracted to technical programs offered through community colleges and technical schools (Stevenson et al. 1998). In our sample, $29 \%$ of black and $29.9 \%$ of Latino students expected to earn an A.A. (associate in arts) degree or special certification from a 2-year college or technical school, compared with fewer Asian (16.9\%), white (17.1\%) and mixed-race (18.1\%) students. Most high school graduates planned to continue their education or training immediately following high school, but $20 \%$ planned to enter military service, work full time or pursue other activities (see p. 61).

Gender differences in preparation and planning for the future were reflected in girls' significantly higher reported grade point average (GPA), educational aspirations, educational expectations, career decidedness and reported benefit from school counseling services.

\section{School counseling services}

For the large majority of seniors $(80 \%)$, school counseling services were perceived as a source of practical information materials to help achieve educational or career goals. Information about financial aid and help with applications and interviews were the services used most often and rated most helpful. However, only a little over half of the students took advantage of these resources. When it came to individual counseling services, career-exploration computer programs, and career-exploration and planning classes, only $28.3 \%$ of the total sample participated. An average of $50 \%$ to $55 \%$ of the students either thought the services were not offered or did not know about them, and $21 \%$ of the students who knew about these services did not use them. Of the 405 students $(28.3 \%)$ who participated in individual counseling, computerized career-exploration programs or classes, the majority ranked them as somewhat helpful or not helpful.

Considering the efforts reported by most of the participating high schools to inform and encourage students to use career centers and counseling services, it is difficult to understand why such a large percentage of students were unaware of them. If these find-

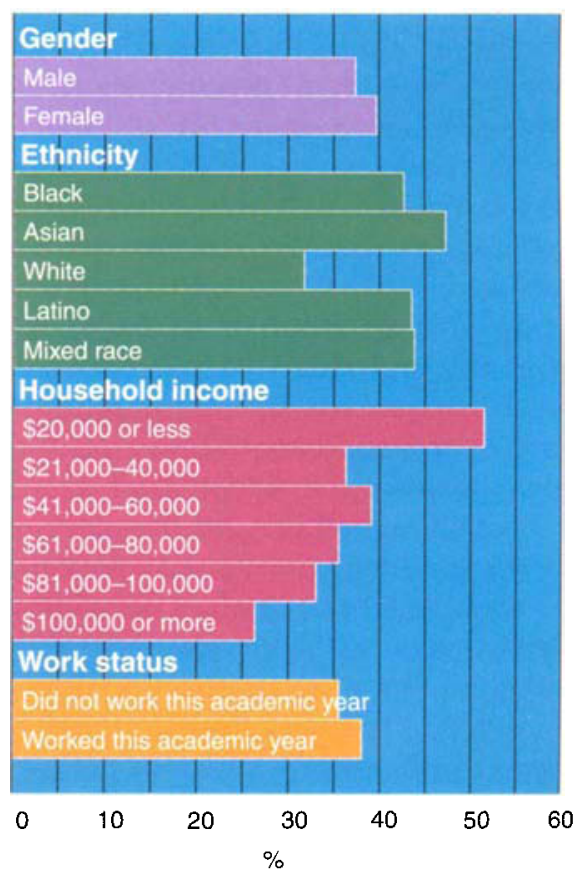

Fig. 3. Characteristics of students for whom aspirations exceed expectations. 


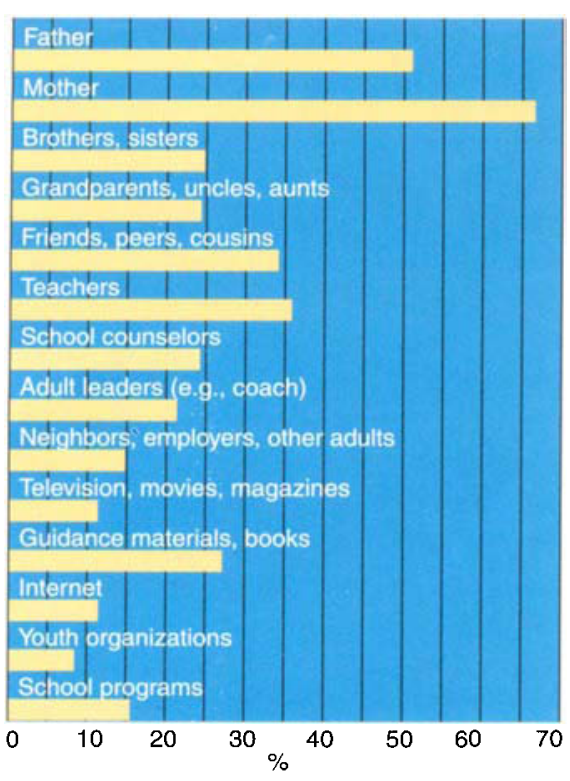

Fig. 4. Students' primary career-planning resources. Bars represent percentages of youth answering that a resource was "very helpful" or "extremely helpful" in planning for their future work.

ings are representative, it appears that a relatively small number of high school students are benefiting from counseling services offered.

One possible explanation is that high school counseling services focus on getting students into college and consequently there is little perceived relevance for students who do not plan to go. In this study, significantly more of the students planning to attend a 4-year college (61.8\%) did use the counseling service than those planning to attend community colleges or technical schools $(52.9 \%)$, enter the military (44.9\%), pursue other activities $(44.7 \%)$, work full time $(36.6 \%)$ or who were undecided $(34.8 \%)$. Other possible reasons may be as straightforward as limited hours of career counseling facilities and students' work and activity schedules. Additionally, the student load per counselor may be so excessive that counselors have little time to spend with any one student and must instead focus on students perceived as having the most critical needs. Further study is needed to understand the factors that would make counseling and career services attractive to a broader spectrum and larger proportion of students.

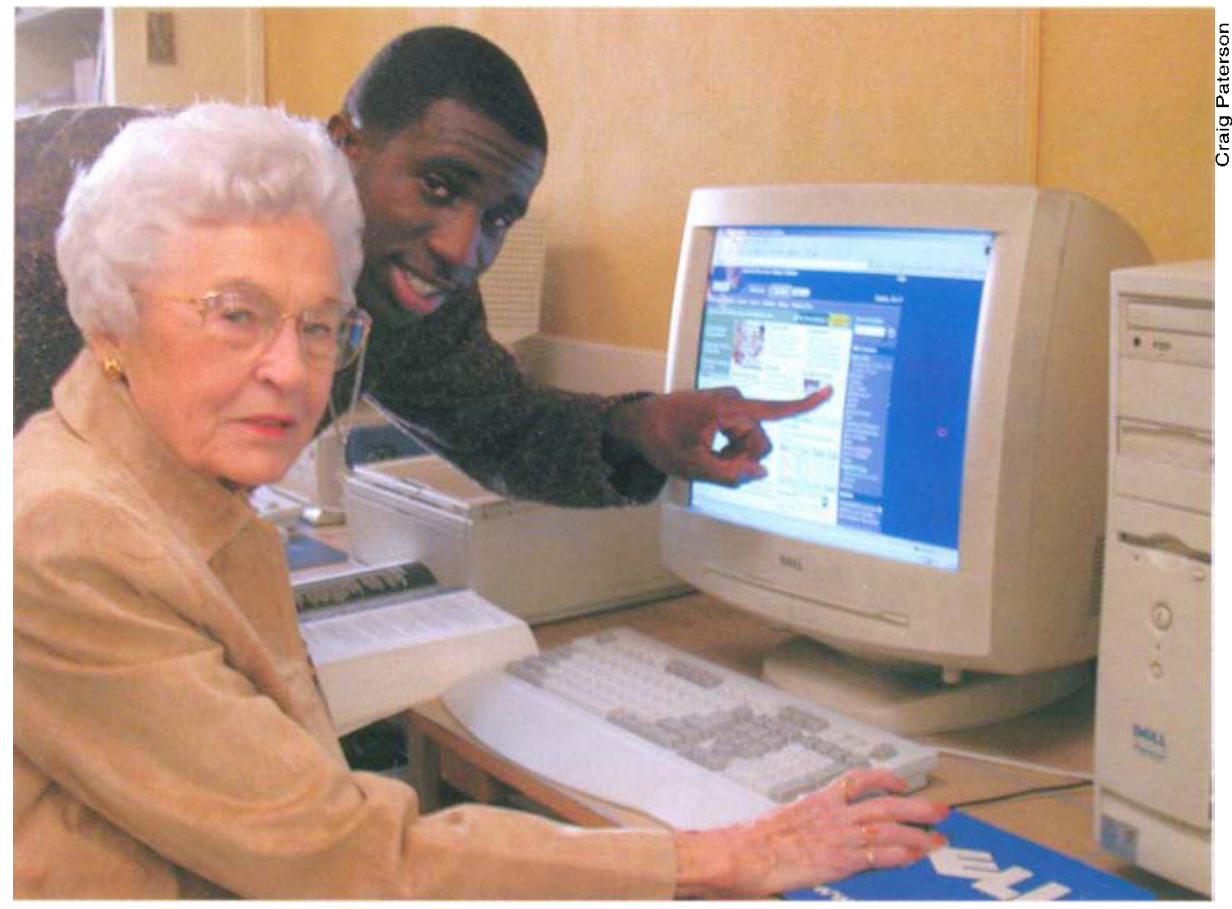

Nearly $90 \%$ of high school students surveyed were involved in extracurricular activities. Emmanuel Yeboah assists Helen Wincentsen at an Internet café in a downtown Vallejo church. In the school-based program, which is assisted by $4-\mathrm{H}$, teenagers learn how to teach computer skills. Yeboah is a senior at Jesse Bethel High School in Vallejo.

\section{Support networks}

The support network enjoyed by an adolescent can have a significant impact on the quality and quantity of information and guidance that he or she receives concerning decisions and planning for the future. A majority of students rated mothers $(66 \%)$ and fathers (51\%) as "very" or "extremely" helpful with regard to planning for future work (fig. 4). These percentages were even higher among students who indicated that they had especially good relationships with their parents. Parents may also have an indirect influence on their children's expectations and plans. Youth whose parents had some college education and/or a higher reported income level were more likely to aspire to a college degree. These findings are compatible with other studies in which the mother's educational level was a key predictor of a child's educational attainment (Rehberg and Westby 1967).

Slightly more than one-third of the students ranked teachers and friends as very important sources of help, and about one-fourth found school counselors, guidance materials and books to be an important resource for career planning. Among the youth participat- ing in extracurricular activities, those involved in student government, newspaper or yearbook, 4- $\mathrm{H}$ and other youth organizations indicated that their adult leaders were a good source of help.

\section{Extracurricular activities}

The American adolescent today mirrors society in many ways, moving ever faster to accomplish more and more. Their typical activities include work, school, extracurricular activities, social relationships, chores at home and community service. Of the students in this study, $88 \%$ were involved in one or more extracurricular activities, typically involving up to 8 hours per week. Community service involved the most students ( $48 \%$ ) but also received the smallest investment of time on a weekly basis ( 1 to 5 hours). In comparison, $46 \%$ of the students participated in sports, reporting an average of 11 to 15 hours per week. Other extracurricular activities, listed in descending order of involvement, were performing arts, religious youth groups, youth organizations, student government, school newspaper or yearbook and 4-H, at up to 5 hours per week each. Note that students may 


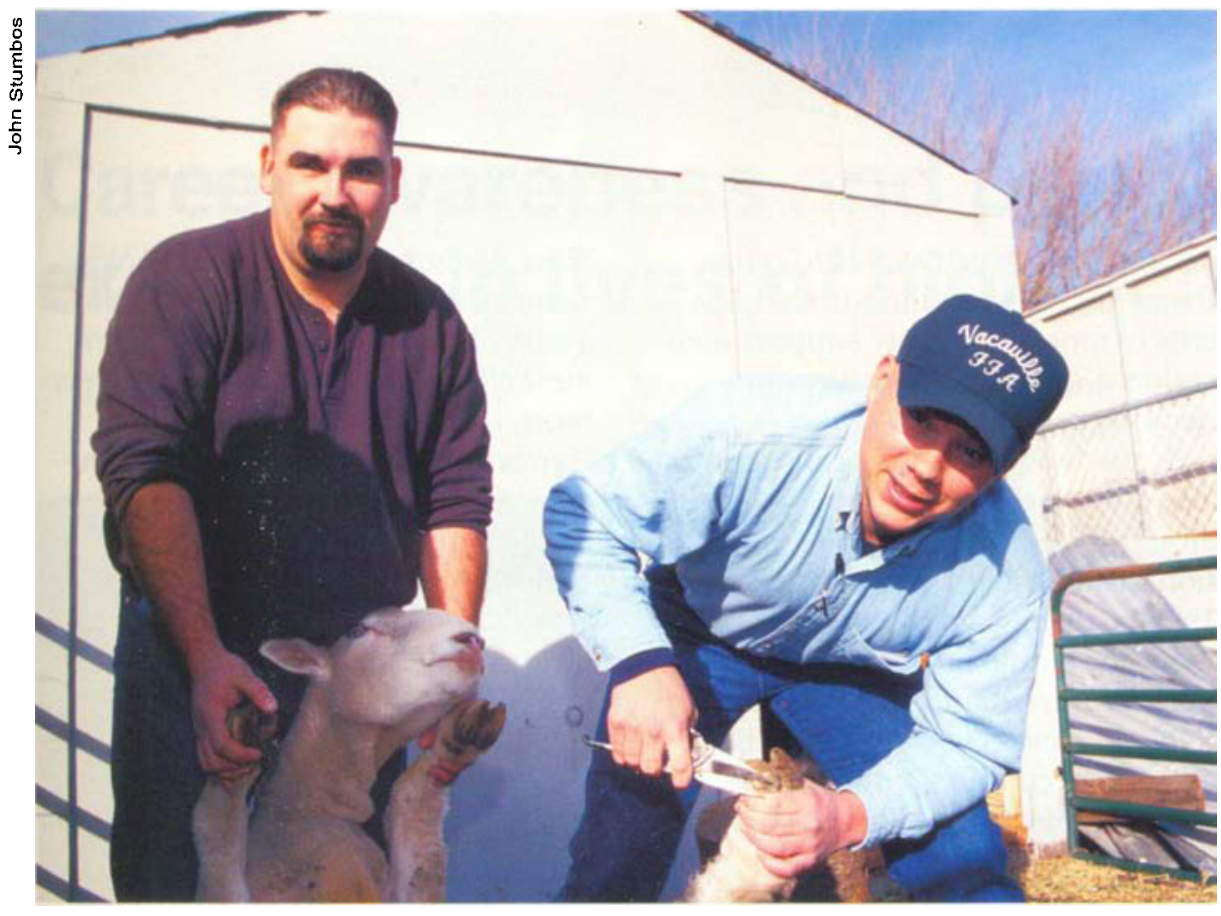

Students involved in extracurricular activities had higher grades, were at lower risk of dropping out, and had the highest educational aspirations. At Vacaville High School, agriculture instructor Nick Johnson, left, helps student Albert Hall trim a sheep's hooves at the school's minifarm. Hall is president of the local Future Farmers of America.

participate in several of these activities simultaneously, and many are not necessarily ongoing throughout the school year. Nor do they consistently demand the same investment of time.

For most activities there were no significant gender differences in level of participation. Participation in sports was $10 \%$ greater for boys than for girls, perhaps because of several sports that are traditionally dominated by boys. Girls' participation in the performing arts and community service was $20 \%$ greater than boys. All ethnic groups were well represented in the different types of activities. Overall participation for black, Asian and white students ranged between $87 \%$ and $89 \%$. For Latino students, it was $81 \%$.

Comparison of young people involved in extracurricular activities with those who were not involved revealed some striking differences. The involved students had higher grades and lower risk of dropping out $(6 \%)$, as well as the highest educational aspirations and expectations. They liked school and differed significantly from uninvolved students in how helpful they perceived adult leaders to be in planning for the future. They also indi- cated that "usually" or "almost always" their "family does fun things together." In contrast, students not involved in any extracurricular activities $(12 \%)$ were twice as likely as involved students to not care if they graduated, to plan to work full time after high school, or to view a community college degree as the extent of their postsecondary education aspirations. Compared to $71 \%$ of the sample, only $48 \%$ of uninvolved students expected to earn a 4-year college degree. This group indicated "lack of goals" as a major obstacle to future plans; $28 \%$ were at risk of dropping out. Although uninvolved students, like involved students, felt that they could "count on parents to help them out," they indicated that their "family does fun things together" "almost never" or only "once in awhile."

However, the involved and uninvolved students were very similar in some areas. About the same percentage of young people from both groups worked (56\% and 53\%, respectively) and there was no significant difference in the number of hours. The percentage of each group working more than 15 hours weekly was also similar ( $33 \%$ and $28 \%$ ), as was the pri- mary reason for working: to earn spending money. In each group, $60 \%$ indicated that they would like help in identifying careers to best suit their personalities, and both categories felt that they needed a clearer idea of their interests ( $47 \%$ involved, $50 \%$ uninvolved) and of their major strengths and weaknesses (53\% involved, $55 \%$ uninvolved). It might be expected that there would be greater differences between involved and uninvolved students with regard to career decision needs, but this turned out not to be the case.

\section{Implications for preparedness}

Our findings indicate that young people would benefit from and are interested in more knowledge about themselves, careers and how to tap the resources that will help them achieve their aspirations. They could particularly use information and guidance on overcoming financial and other perceived educational barriers. In California, an excellent higher education system provides a variety of pathways to a college education, but many students need help in learning how to make wise choices and tap into scholarships, grants and loans.

Students also want help in evaluating their interests and aptitudes in order to gain a clearer idea of what field of work would hold the greatest opportunities for satisfaction and success. Considering the dynamic nature of the workplace, it is important that people entering the workforce understand their strengths and how to use them effectively in diverse situations. Finally, young people would be well served by opportunities to gain firsthand knowledge about possible career opportunities that fit their interests and aptitudes. Knowledge in all of these areas needs to be developed through a wide variety of experiences in the home, school and community.

Through this study we identified some weaknesses and strengths in the support networks of youth. We found that school counseling services are not attracting most students to use their services - especially those who may 


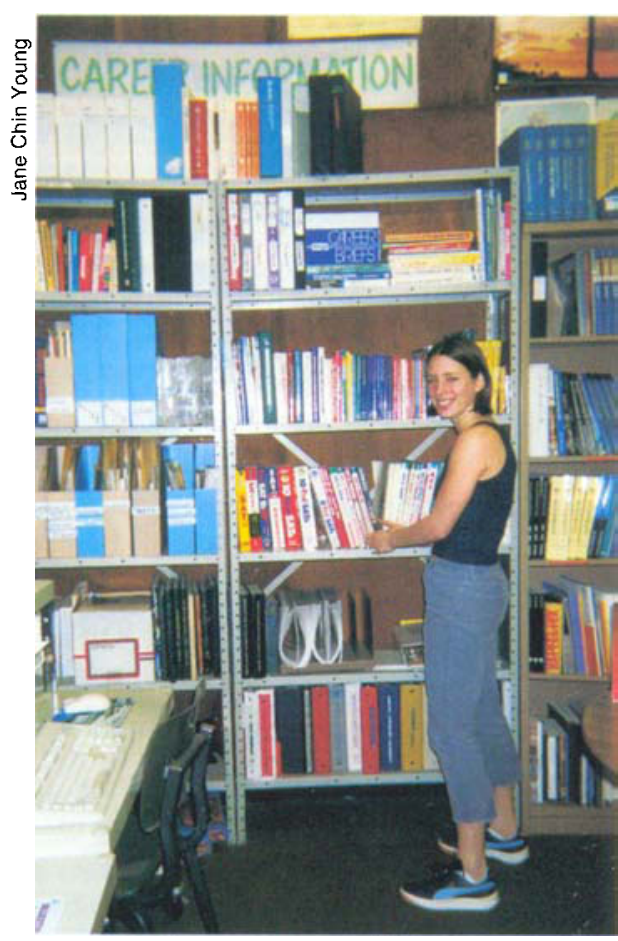

Despite many schools' best efforts, students found career-planning services only marginally helpful. At San Marin High School in Novato, sophomore Amber Miller investigates the career center.

need them most. And the majority of students who do use the services find them only marginally helpful.

It has always seemed logical for the public high-school system to be the primary provider of guidance about future work and education. If this continues to be the case, schools should look more closely at the effectiveness of these services, as well as how they are "marketed" to students. It is only fair to say that responsibility also rests with the student to be informed and to make the most of their school's resources. If the needs of those who stay in school are not being met, it is even more discouraging to think about those youth who drop out along the way.

The students in this study felt that their parents were the most helpful people in their support network. However, we do not have a clear understanding of what parents do that is perceived as helpful. Further research will provide insight about the parentadolescent dynamics that influence career decision-making and preparation for the workplace. This insight can help schools and youth development organizations such as $4-\mathrm{H}$ to refine their programs, and in turn help parents to more effectively support their children's career exploration and decision-making.

Knowledgeable, caring, listening adults form the support network that all youth need as they make the transition to adulthood and work (SCANS 1992). Creating a strong support network for Latino and black youth is especially important; their comparatively low expectations for further education, coupled with a current high dropout rate, is cause for serious concern. Although there has been a dramatic decrease in the school dropout rate among all ethnic groups since 1992, in 1998 the rate was $16.3 \%$ for Latino and $17.4 \%$ for black youth, in comparison to $7.5 \%$ and $6.3 \%$ for white and Asian students, respectively. The magnitude of the problem becomes more apparent when one considers that during the same year, $40.5 \%$ of the 5.7 million children enrolled in California public schools were Latino and $8.8 \%$ were black (California Student Trends 2001; Clark 2000).

Preparing to enter the workforce as a self-sufficient, responsible member of society is a developmental process that is affected by experiences from preschool through young adulthood. As the world of work becomes more dynamic and complex, we need to further our understanding of the workforce preparation process and develop effective ways of meeting young people's needs for knowledge, skills and guidance in this important aspect of their lives.

\section{E.R. Madsen is Research Associate, 4-H Center for Youth Development, Depart- ment of Human and Community Develop- ment, UC Davis; A. Brosnahan and I. \\ Valdez are 4-H Youth Development Advi- sors, San Joaquin County and Sutter and Yuba counties, respectively; S. Donohue is Family and Consumer Science and Youth Development Advisor, Butte County; T. McAllister is retired 4- $H$ Youth Develop-}

ment Advisor, Humboldt and Del Norte counties; and M.T. Braverman is 4-H Youth Development Specialist, Department of Human and Community Development, UC Davis. The UC Division of Agriculture and Natural Resources provided funding for this study.

\section{References}

Bergman G, Killen M. 1999. Adolescents' and young adults' reasoning about career choice and the role of parental influence. $J$ Res Adolescence 9(3):253-75.

California Student Trends. 2001. Ed-Data, State Report. www.ed-data.k12.ca.us/state.

[CCAD] Carnegie Council on Adolescent Development. 1989. Turning Points: Preparing American Youth for the 21st Century; The Report of the Task Force on Education of Young Adolescents. Carnegie Corp of NY. $106 \mathrm{p}$.

Clark WA. 2000. Immigration, high fertility fuel state's population growth. $\mathrm{Cal} \mathrm{Ag}$ $54(1): 11-8$.

Greenwald J. 1997 June 20. Where the jobs are. Time:54-61.

Harren VA. 1979. A model of career decision-making for college students. $J$ Vocation Behav 14:119-33.

Lamborn SD, Mounts NS, Steinberg L, Dombusch SM. 1991. Patterns of competence and adjustment among adolescents from authoritative, authoritarian, indulgent and neglectful families. Child Dev 62:1049-65.

Rehberg RA, Westby DL. 1967. Parental encouragement, occupation, education and family size; Artifactual or independent determinants of adolescent educational expectations. Social Forces 362-74.

Santrock JW. 1995. Life-Span Development. Madison, WI: Brown \& Benchmark.

[SCANS] Secretary's Commission on Achieving Necessary Skills. 1991. What Work Requires of Schools: A SCANS Report for America 2000. Washington, DC: US Dept Labor. $61 \mathrm{p}$.

SCANS. 1992. Skills and Tasks for Jobs: A SCANS Report for America 2000. Washington, DC: US Dept Labor.

Stevenson DL, Kochanek J, Schneider B. 1998. Making the transition from high school: Recent trends and policies. In: Borman K, Schneider B (eds.). The Adolescent Years: Social Influences and Educational Challenges; 97 th Yearbook of National Society for Study of Education. Chicago: Univ Chicago Pr. p 207-26.

Trice AD. 1991. A retrospective study of career development: I. Relationship among first aspirations, parental occupations and current occupations. Psych Rep 68:287-90.

Vondracek FW. 1993. Promoting vocational development in early adolescence. In: Lerner RM (ed.). Early Adolescence: Perspectives on Research, Policy and Intervention. Hillsdale, NJ: Erlbaum. p 277-93. 